\title{
The Effect of Team Leader Skills and Competencies Team: A Structural Equation Modelling Approach
}

\author{
Nordin Zakaria $^{1} \&$ Ayankunle Taiwo ${ }^{1}$ \\ ${ }^{1}$ Universiti Teknologi PETRONAS, Malaysia \\ Correspondence: Nordin Zakaria, Universiti Teknologi PETRONAS, Malaysia. E-mail: \\ nordinzakaria@petronas.com.my
}

Received: February 7, 2013 Accepted: April 4, 2013 Online Published: June 1, 2013

doi:10.5539/ass.v9n7p151 URL: http://dx.doi.org/10.5539/ass.v9n7p151

\begin{abstract}
Team work has been emphasized as an important way of getting a piece of job done effectively in organizations by the participation of every member of the team. However, leadership skills and other factors do affect team performance. This study investigated the factors that influence the effective performance of research clusters team leaders and team members in the Universiti Teknologi PETRONAS (UTP). A survey was conducted and a hundred and seventy six (176) faculty staffs and members of different research cluster in UTP participated in the study. Structural equation modelling (SEM) technique was employed to analyze the data. The outcomes of the study shows that team leaders Human Skills and Team self Evaluation significantly influence the effective performance of the team. Also, team self evaluation have a direct effect on technical skills. Implication for practise and future works was also discussed.
\end{abstract}

Keywords: Lavaan-R, leadership, team, SEM, Malaysia

\section{Introduction}

The quest for increase performance, mentoring, teambuilding and leadership is of growing concern in the academia. The study of leadership related issues is of great importance to clarify the essential leadership style that can unsure success of an organization (Winston \& Dunkley, 2002). In this regard, it is of paramount importance to identify skills and competencies that are required by educationist/researchers to become successful leaders and effective team members.

A leader can be defined as an individual that "moves people toward shared dreams; connects what a person wants with the organization's goals; values people's input and gets commitment through participation and soothes fears by giving clear direction in an emergency" (Goleman, 2002: 55). Educationists who are research cluster leaders are required to source for funds and resources that would enable their team deliver set goals and objectives. Accordingly, the leadership skills and competencies related to fundraising becomes a desired asset that assists the leader who is expected to persuade the external financiers the deliverables of the research and the benefits the output of the research to such investors. Performance evaluation are currently required standard practice in both the private sector and the public sector (Patterson, 1987; Moore \& Rudd, 2004). Although it has been given limited attention, study of team leaders in the academia is important. Druskat and Wheeler (2001) suggested that team leaders do influence the environment of the team they lead. The leader of a team does not only influence the environment but the processes and behaviour (Schein, 1992; Dickson et al., 2001; Koman \& Wolff, 2007). However, there has been inadequate research linking the team leadership skills to performance. Some of the other previous empirical studies investigated the effect of team efficiency, motivation on team performance (Sivasubramaniam et al., 2002; Dickson et al., 2001).

In most tertiary institution, performance indices such as publications and number of supervised students are used as key performance index for faculty staffs. However, measuring the performance of a team of researchers is also important but factors such as the leaders' skills and competencies could affect team performance. Leaders are also required to effectively lead a team of researchers in attaining deliverable goals of a mission oriented research and mentor junior researchers in perfecting their competencies in conducting state of the art research. In this regard, the quality and the depth knowledge of the cluster leaders in the categorised research area becomes valuable tools in becoming an effective team leader. 
Furthermore, the ability of the team members to do a self appraisal and evaluate their contribution to the team is key to the completion of task and projects been conducted by the specific research cluster. Therefore, inherent self evaluation skills possessed by individual members to specifically evaluate themselves towards their performance and value added to the group assist the leaders to focus more on proactive decision making rather than problem solving decisions. Many studies have focused on the sustaining effective work teams (Shahmandi, Silong, Ismail, Abu-Samah \& Othman, 2011). However, little empirical studies have investigated the effect of skills and competencies of team members or the team leaders in the academia, most especially in the south Asian pacific nations. The management of University Teknologi PETRONAS (UTP), created the Mission Oriented Research (MOR) alongside different research clusters in each department to boost focused based research that could launch the Institute to higher recognition amongst the research focused Universities in Malaysia. Each of the research clusters are led by senior faculty staffs with leading academic and research achievements. Members/team members of the research clusters are faculty staffs with special abilities and interest that adds value to the research team. Leaders such as Deans, Head of Department and Head of research groups in various research universities requires adequate leadership skills to perform effectively in their respective roles (Shahmandi, et al., 2011). The objective of this study is to investigate the leadership skills and competencies that enhance the performance of research groups in a higher education environment.

\section{Literature Review}

\subsection{Importance of Teams in the Workplace}

Fisher,Hunter \& Macrosson (1997) have discussed the difference between a team and a group. A group can be defined as "a collection of individuals who are interdependent in their tasks, who share responsibility for outcomes, who see themselves and who are seen by others as an intact social entity embedded in one or more larger social systems and who manage their relationships across organizational boundaries" (Cohen \& Bailey, 1997: 241). While a team can be defined as "a distinguishable set of two or more individuals who interact interdependently and adaptively to achieve specified, shared, and valued objectives" (Morgan, Glickman, Woodard, Blaiwes \& Salas, 1986: 3). The scope employed in this study involves individuals who interact interdependently to achieve shared, valued and specific objectives; thus they are referred as team throughout the paper. Despite literatures on the difference of the two teams, studies have used the terms interchangeably because of the unification of the terms as regards the output (Cohen \& Bailey, 1997: 241; Stubb et al., 2005).

In many organizations, teams are increasingly becoming crucial work units to the success of the organizations (Cohen \& Bailey, 1997; Goleman, 1998; Appelbaum, Abdallah \& Shapiro, 1999, Stubb, 2005). According to Stubbs et al (2005), early parts of the last two decades shows that $80 \%$ of organizations with more than 100 employees uses work team, and the trend has greatly increased till the present time because of the significant outputs of the team work.

The increase in the use of teams in organizations has made opened up the growing concerns of "what makes the team effective"? The team members or the team leaders? Many research universities have created research cluster and groups to improve the quality of research output of universities. Many studies have focused on the sustaining effective work teams. However, little empirical studies have investigated the effect of skills and competencies of team members or the team leaders in the academia, most especially in the south Asian pacific nations.

Knowing that teams are important units in any workplace, it is important to investigate and understand factors that affect the performance of the teams. Some past research on team member/leader skills and competences that affects the performance of the team is hereby discussed in the following section.

\subsection{Leadership Skills and Competency}

Moore and Rudd (2004) developed a model for the essential leadership skills and corresponding competencies for leaders. The competencies were classified into different category such as Human, Conceptual, Communication, Emotional Intelligence, Industry Knowledge and Technical Skills. Moore and Rudd (2005) conducted a follow up study to empirically validate their previous study on leadership as perceived by team members and found six important leadership domains including perceived proficiency of the leaders. It was discovered that technical skills was a domain that was of average proficiency by the leaders. Some of the skills areas of leadership competencies are briefly discussed in the following sections.

\subsubsection{Human Skills}

Human skill is the leaders "ability to work effectively as a group member and to build cooperative effort within the team he leads" (Katz, 1955: 34). Several studies have built on the Katz analysis of Human Skills a crucial 
and important skill of a leader. Moore and Rudd (2004) characterised the human skills of a leader as; relationship builder, talent identification, awareness of cultural diversity, ability to objectively evaluate members, be a team player and openness. Human skills and competencies is about working and dealing with people rather than technologies or processes. Human skill could be seen as the manner an individual in a team or group sees his superiors or subordinates, equals and how he/she responds respectively.

A leader, who is the administrator of a team, is expected to create an environment with assurance and security for team members to express themselves without fear, by motivating them to actively contribute to planning and execution of the plan. Shahmandi, Silong, Ismail et al. (2011) suggested that effective academic leaders need a number of specific leadership skills and competencies to lead. These skills and competencies are required for research universities to move towards excellence. Based on the argument above, the following hypothesis is proposed:

\section{H1: Human skill has a significant effect on effective performance.}

\subsubsection{Conceptual Skill}

Conceptual Skill is the "involves the ability to see the enterprise as a whole"(Katz,1955,pg36). This implies that the leader should possess ability to identify various functionality of the team and their dependency on one another. The ability of the leader also makes him to visualise how the changes that occur in any part of the team affects the team as a whole and its relation with other teams in the organization. Moore and Rudd (2004) characterised the conceptual skills of a leader as: Strategic/sequential planning; Organizational change Goals (set and achieve); Critical/creative thinking and adequate decision making.

Importantly, the success of the decisions made by the team leader largely depends on the level of conceptual skills that is inherent in the leader. For example in an academic research team, if a training and development policy is made it is of paramount importance that the effects on the finance, process, duration, output/deliverables and the people involved should be given due consideration. It does become critical for all participants of the policy to adhere to the details of the policy in order to achieve the main aim of the policy. When each team member understands the importance of the policy change and the strengthened relationship in the team then the team member would be most glad in administering the policy, thus the probability of success of the team increases. The ability of a leader to visualize the team as a whole and how the team will contribute to fulfilling its part in the vision of the organization is an important skill that a leader needs lead a team effectively (Shahmandi et al., 2011). However, the authors did not investigate the direct influence of conceptual skills on team performance. Therefore, based on the argument above, the following hypothesis is proposed:

\section{H2: Conceptual Skill has a significant effect on effective performance.}

\subsubsection{Technical Skill}

Technical skill can be defined as the "understanding of, and proficiency in, a specific kind of activity, particularly one involving methods, processes, procedures, or techniques" (Katz, 1955: 34). Technical skills can be seen when an expert is performing his or her duties ie an engineer, surgeon or musician. Amongst the leadership skill that are required of a good leader, technical skill is the one that is quite visible to the rest of the team members. When the leader displays his or her prowess as a guide for the team members, it fosters respect and willingness to follow such a leader so as to able to acquire such technical skill as the leader possesses. Moore and Rudd (2004) classified technical skills into the following: Competent (technical area) Internet skills; Computer skills; Finance/fundraising; Budgeting. A leader with the above skill set can use his skill to effectively lead a team. Pagon, Banutai, \& Bizjak (2008) argued that technical skill is one of the leadership skills area that is of importance for leaders and members of their team to perform effectively. However, the author did not investigate the direct influence of technical skills on team performance. Therefore, based on the argument above, the following hypothesis is proposed:

\section{H3: Technical Skill has a significant effect on effective performance.}

\subsubsection{Team Self-Evaluation}

Team self evaluation can be described as the ability of teams to conduct self evaluation on meaningful output of the team, while they monitor their strengths and weaknesses in relation to business operation (Hamme, 2003). In an investigation on the performance of teams, Druskat (1996) suggested that high-performing teams do employ self evaluation strategy in order to investigate information about their performance so that they can then compare with other teams invariably they know where they stand and seek how to improve the performance of the team. Edmondson (1999) corroborated the argument of Druskat when he found that team members do perform self-diagnosis, while teams that seek information about their performance do actively monitor their performance 
for improvements. Studies have also shown that team self-evaluation positively influence team effectiveness (Stubbs \& Messer, 2002; Druskat, Messer, Koman \& Wolff, 2003). However, the author did not investigate the direct influence of team self evaluation on team performance neither was the influence on team self evaluation on other leadership skills investigated. Therefore, based on the argument above, the following hypotheses are proposed:

H4: Team Self Evaluation has a significant effect on effective performance.

H5: Team Self Evaluation has a significant effect on Technical Skills.

\subsubsection{Team Effective Performance}

The competencies and skills sets of team members/leaders have been shown to be significantly related to performance (Hirokawa, DeGooyer, \& Valde, 2000; Goleman, 2001; Dulewics \& Higgs, 2002; Stubbs \& Messer, 2002; Druskat, Messer, Koman \& Wolff, 2003; Stubb, 2005). This research validates the previous research in other domain that the competencies and skills of teams members/leaders on effective performance of the teams as perceived by the Lecturers of UTP that makes up the teams of different research cluster of the Institute is significant.

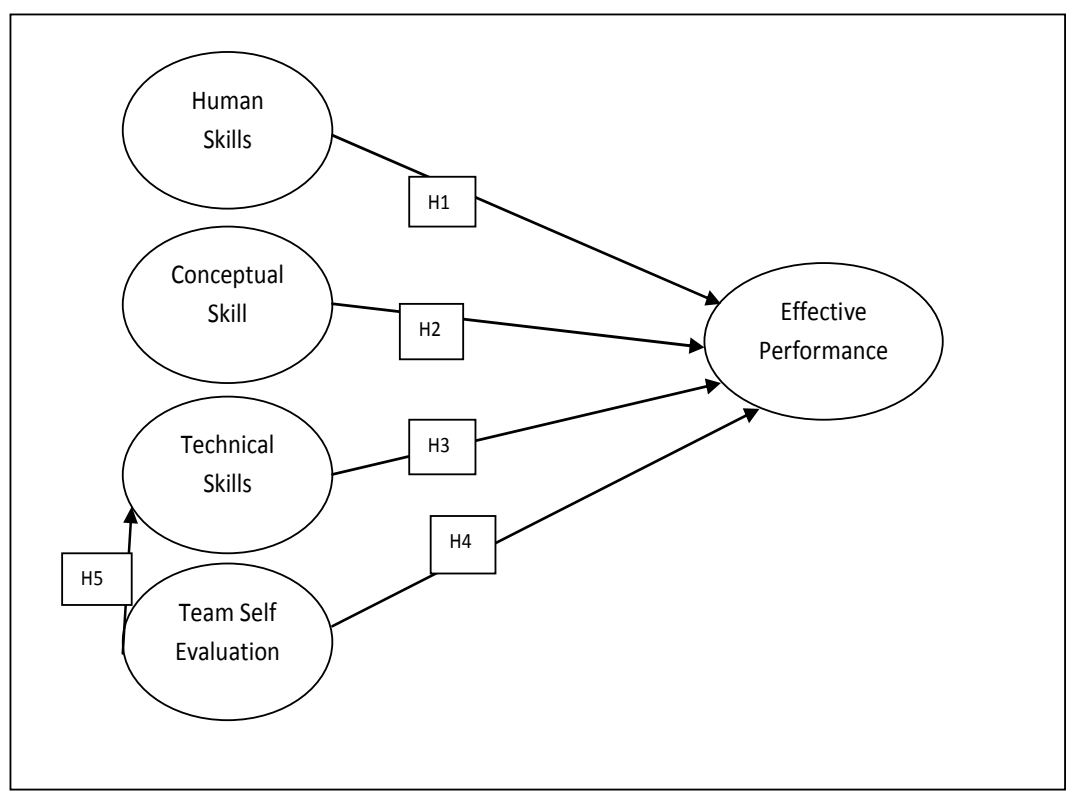

Figure1. Research model

\section{Research Methodology}

The quantitative research paradigm was employed for this study. The dimensions used in this study were adapted from previous studies. The research model and hypothesis was formulated based on the previous works and literature. Constructs such as Human skill, conceptual skill, technical skill, team self evaluation were adapted from the work of Moore \& Rudd (2004), while effective team performance was drawn from the work of Stubb (2005). The above authors used the work of Goleman, (1998); Katz (1955) and Robbins, Bradley, \& Spicer (2001) as baseline to investigate leadership skills and competencies. Based on the outcome from previous studies, the research model and hypotheses was formulated. Therefore we have four hypotheses.

\section{H1: Human skill has a significant effect on effective performance.}

\section{H2: Conceptual skill has a significant effect on effective performance.}

H3: Technical skill has a significant effect on effective performance.

\section{H: Team Self Evaluation has a significant effect on effective performance.}

\subsection{Sampling Population and Design}

The study population involves about 300 teaching staffs of University Technology PETRONAS, Malaysia. The faculty staffs that participated in the study are researchers that are members of a research cluster or Mission Oriented Research (MOR) group in UTP. The faculty staffs are full time employees of the institute that actively 
conducts and carry out their research duties at the university. Each of the research clusters is directed by the leader of the team.

\subsection{Data Collection and Procedure}

The data collection technique that is used for any survey is of paramount importance to the outcome of the survey study. Therefore, we employed the use of randomized sampling technique for the selection of the researchers in the research clusters. Three research assistant with prior experience in survey data collection was trained and employed for data collection. Faculty staffs were randomly selected and approached to participate in the survey. The data collection was in two stages. The first stage was for the pilot study with 10 participates, this was to finalise the design of the items on the questionnaire. Ten (10) researchers were selected randomly to answer the questionnaire. The feedback from the pilot study gave two important suggestions. First, that there are some question that needs rewording because they were seemingly personal in nature. Secondly, that the average time taken for respondents to complete the survey questions is 10minutes. The second stage was the final stage where the questionnaire were randomly distributed and collected over a period of about two weeks from $22^{\text {nd }}$ December 2012 to $3^{\text {rd }}$ January 2013. Over all, one hundred and seventy six (176) useful responses were returned, given a response rate of $58.7 \%$. This is however satisfactory as Sekaran (2003) recommends response rate above $30 \%$.

\subsection{Instrument Preparation and Design}

The instrument employed in this study was adapted from the work of Moore \& Rudd (2004) and Stubb (2005). The above authors used the work of Goleman (1998), Katz (1955) and Robbins, Bradley, \& Spicer (2001) as baseline to investigate leadership skills and competencies. The five dimensions used in this study are: Human skill, conceptual skill, technical skill, team self evaluation and effective performance. The instrument is divided into two parts. The first part (A) consists of brief questions that relates to demographic information about the respondents. The second, part (B) was specifically designed to capture latent variables that represents the skills and competencies of team members and leaders. Each of the items measures at least four items. A seven (7) point Likert scale was adopted for the study with values range from: $1=$ strongly disagree, $2=$ disagree, $3=$ partially disagree, $4=$ undecided, $5=$ partially agree, $6=$ agree and $7=$ strongly agree. The items in the questionnaire are in (Appendix A).

\section{Results and Data Analysis}

\subsection{Descriptive Statistics}

Regarding the demographic statistics, 176 respondents successfully completed the survey. It also shows that the gender distribution is quite uneven with 130 male respondents $(73.9 \%)$, while only 46 female respondents (26.1\%) participated in the survey. A total of 26 different research clusters were dully represented by the respondents. A total of 167 research cluster (team) members participated in the study while 9 research cluster (team) leaders participated in the study.

Regarding the total numbers of years the participants have spent in UTP, 55 participants have duration of between 1-3 years which is the highest with $31.3 \%$, the second highest have spent 10-12years with a total number of 44 (25\%). Followed by 35 (19.9) participants that have spent of duration between 4-6years. 21 (11.9\%) of the participants have spent 13-15 years, followed by $19(10.8 \%)$ of the participants with 7-9years duration.Lastly, 2 (1.1\%) participants have spent 16-18years while none of the participants have spent up to 19 year in UTP.

Regarding the rank of the participants in their various departments, Senior Lecturers are the group with the highest number of participants with 61 (34.7\%). Second highest are the Lecturers with a total of $54(30.7 \%)$ participants. Followed by Associate Professors with a total of $41(23.3 \%)$ participants. There are 13 (7.4\%) postdoctoral researchers, $6(3.4 \%)$ full professors and 1(0.6) research scientist.

\subsection{Convergent and Discriminant Validity}

After the reliability of the constructs has been ascertained, the convergent and discriminant validity was assessed. Two tests was used to evaluate the convergent validity. The composite reliability (CR) of each the constructs in the study is quite above 0.7 (See Table1). Further, the average variance extracted (AVE) of all the dimensions exceeded 0.5 (See Table1). Both the CR and the AVE satisfied the recommended threshold suggested by Hair et al. (2006). Table 1 also shows the corresponding factor loadings that resulted in the CR and AVE. Furthermore, Table 1 depicts that fit indices measurement such as Root Mean Square Error of Approximation (RMSEA) and Comparative Fit Index (CFI) satisfactory met the recommended benchmark (Hair et al., 2006; Kline, 2005; Hu \& Bentler, 1999) as depicted in Table1 and Table 3. 
Table 1. Discriminant validity of measurement model

\begin{tabular}{|c|c|c|c|}
\hline Variables & Factor Loadings & Composite Reliability & Average Variance Extracted \\
\hline \multirow{5}{*}{ Human Skills (HS) } & $\mathrm{HS} 1=0.80$ & \multirow{5}{*}{0.8786} & \multirow{5}{*}{0.5925} \\
\hline & $\mathrm{HS} 5=0.71$ & & \\
\hline & HS6 $=0.72$ & & \\
\hline & HS7 $=0.85$ & & \\
\hline & $\mathrm{HS} 9=0.76$ & & \\
\hline \multirow{4}{*}{ Conceptual Skills (CS) } & $\mathrm{CS} 1=0.77$ & \multirow{4}{*}{0.9084} & \multirow{4}{*}{0.7138} \\
\hline & $\mathrm{CS} 2=0.91$ & & \\
\hline & $\mathrm{CS} 3=0.90$ & & \\
\hline & $\mathrm{CS} 6=0.79$ & & \\
\hline \multirow{3}{*}{ Technical Skill (TS) } & $\mathrm{TS} 1=1.00$ & \multirow{3}{*}{0.9025} & \multirow{3}{*}{0.7584} \\
\hline & $\mathrm{TS} 1=0.87$ & & \\
\hline & $\mathrm{TS} 1=0.72$ & & \\
\hline \multirow{3}{*}{ Team Self Evaluation (TSE) } & $\mathrm{TSE} 1=0.80$ & \multirow{3}{*}{0.7963} & \multirow{3}{*}{0.5720} \\
\hline & TSE $2=0.86$ & & \\
\hline & TSE $4=0.58$ & & \\
\hline \multirow{4}{*}{ Effective Performance (EP) } & $\mathrm{EP} 1=0.81$ & \multirow{4}{*}{0.8947} & \multirow{4}{*}{0.6852} \\
\hline & $\mathrm{EP} 2=0.95$ & & \\
\hline & $\mathrm{EP} 3=0.90$ & & \\
\hline & $\mathrm{EP} 4=0.61$ & & \\
\hline
\end{tabular}

\subsection{Structural Model Testing}

The structural model was evaluated by standardized path estimates and z-values using Lavaan- $R$ 2.15.1. The path coefficients of the present latent variables are direct impact of the rationale variables to the dependent variable. Where absolute $\mathrm{Z}$-value greater than $1.96(\mathrm{a}=0.05)$ implies significant level. Figure 2 and Table 2 depicts the path coefficient results where three (3) of the five (5) hypotheses were supported.

As predicted by H1, Human Skill is significant and positively predicts effective performance with ( $\beta=0.499$, $\mathrm{p}<0.05$ ). Surprisingly, $\mathrm{H} 2$ and $\mathrm{H} 3$ failed to significant and positively predict effective performance with ( $\beta$ $=0.006, p<0.05)$ and $(\beta=0.110, p<0.05)$ respectively. As predicted by $\mathrm{H} 4$, team self evaluation is significant and positively predicts effective performance with $(\beta=0.338, p<0.05)$. Lastly, $\mathrm{H} 5$ suggest that team self evaluation is significant and positively predict technical skill with $(\beta=0.380, \mathrm{p}<0.05)$. 


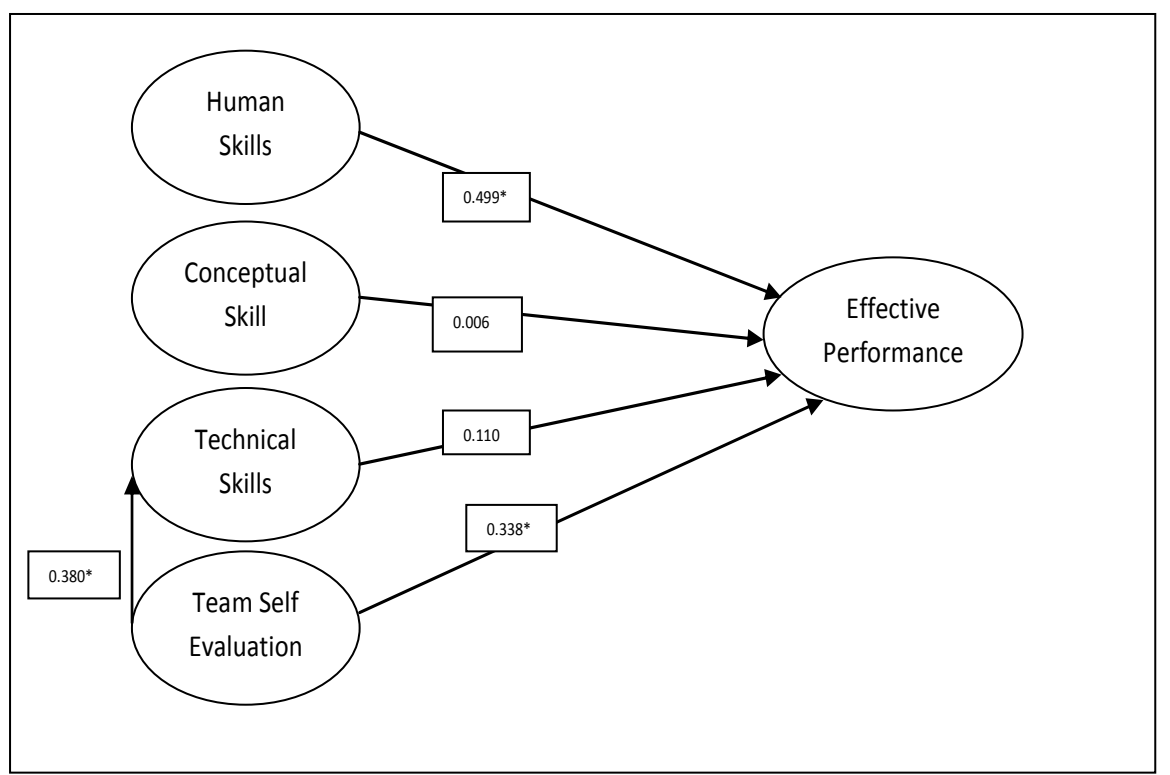

Figure 2. Lavaan-R structural estimation $(*=$ significant path)

Table 2. Path coefficient and hypothesis testing

\begin{tabular}{llllll}
\hline Hyp & DV & IV & $\beta$ & Z-value & Conclusion \\
\hline H1 & EP & HS & $0.499^{*}$ & 2.925 & Accepted \\
H2 & EP & CS & 0.006 & 0.033 & Rejected \\
H3 & EP & TS & 0.110 & 1.627 & Rejected \\
H4 & EP & TSE & $0.338^{*}$ & 3.152 & Accepted \\
H5 & TS & TSE & $0.380^{*}$ & 4.507 & Accepted \\
\hline
\end{tabular}

Hyp=Hypothesis, DV =Dependent variable, IV Independent variable, $\beta=$ Standardised Loading.

Also, regarding the goodness of fit (GoF), Chi square of 379.563, degree of freedom (df) of 142, X2/df (ratio) of 2.67, RMSEA of 0.097 , SRMR of 0.070 , CFI of 0.907 , TLI of 0.888 . The values satisfied the recommendation value as shown in Table 3 . The results suggest that the measurement model adequately fits the data. Therefore, the proposed model is acceptable.

Most importantly, the $\left(\mathrm{R}^{2}\right)$ variance of the model is 0.701 , this implies that factors in the model explained performance with a degree of about seventy $(70 \%)$ percent. This implies that there exist other factors that are not inclusive in the model with about $30 \%$ variance.

Table 3. Absolute fit indices of the proposed model

\begin{tabular}{lll}
\hline Fit Indices & Benchmark & Value \\
\hline$\chi 2$ & NA & 379.563 \\
$d f$ & NA & 142 \\
$P$-value & NS & 0.000 \\
$\chi 2 / d f$ & $<3.0$ & 2.67 \\
RMSEA & $<0.10$ & 0.097 \\
SRMR & $<0.10$ & 0.070 \\
CFI & $>0.90$ & 0.907 \\
TLI & $>0.80$ & 0.888 \\
\hline
\end{tabular}

$\chi 2=$ Chi-Square, $\mathrm{df}=$ degree of freedom. $\mathrm{p}$-value=probability value, RMSEA=Root mean Square error of approximation, $\mathrm{CFI}=$ Comparative fit index, $\mathrm{TLI}=$ Tucker-Lewis Index, $\mathrm{SRMR}=$ Root Mean Square Residual, $\mathrm{NS}=$ Non Significant NA=Not Applicable 


\section{Discussion}

The purpose of this study was to empirically investigate the factors (skills and competencies) that influence effective performance of research team/clusters in Universiti Teknologi PETRONAS, Malaysia. For this goal constructs adapted from other studies were used to reflect the Leaders skills and competencies. This study empirically extended the work of Moore and Rudd (2004) and we applied it in a research community. The result of the measurement model gave support to the research model. Overall, the study shows that the model possesses predictive ability to identify the skills and competencies that are available within the UTP research community and the explanation of its effects on the performance of the research teams/clusters.

Previous studies suggest that human skills and Team self evaluation are important in assisting team leaders to build an effective team (Moore \& Rudd, 2004). Similarly, the present study is equally in agreement with previous studies and shows that Human Skills and Team self evaluation contains competencies that reveals significant effect on team and leadership performance. First, The Human Skill dimensions reveal five important competencies which are:

1) Demonstrate respect for others in the team: This reveals that the team members perceive their leaders to demonstrate respect for other researcher in the team.

2) Possesses effective leaders in the research cluster in UTP: This implies that staffs and researchers that participated in the study believe that there exists effective leadership competency in their respective research team.

3) creation of environment that creates room for diversities of others: This implies that the respondents perceive that the leadership of their research cluster demonstrate accommodating competency that creates room for the diversity of other researcher that are of different culture, religion, principles and ideology

4) Personal strengths is identified and appreciated: Also, this shows that the team leaders demonstrate competency that identifies the strengths and weakness of team members.

5) Support for organizational leadership development programs: The study also reveals that the leaders support team members towards self development. This shows that the leaders demonstrate the competency of leadership development programs. This competency is very important because it allows the emergence of new leaders in the case where a leader leaves.

These competencies have been explored and revealed in previous studies as important competences for leaders to possess (Moore \& Rudd, 2004; Moore \& Rudd, 2005).

Secondly, The Team Self Evaluation dimensions reveal three important competencies which are:

1) Discussing what helps or hurts the performance of the team: The ability of the team leader and team members to discuss what assist and hampers to progress of the research cluster goes a long way in improving the performance of the team.

2) Awareness of the mood in the team and how it affects teamwork: It is important for the team leader and the rest of the team to be aware and accept different moods in the team while discretion and leadership skill is needed to resolve matters. Human mood is much of a personality issue and it is quite a challenge to counter. It is important for the leader to possess such competency that recognizes the mood in the team and how to best use it to the advantage of the team.

3) Comparison with other research team/clusters: A little healthy competition is all that it takes to fosters teams into effective performance. The ability of the leaders to justly make healthy comparison with other team fosters team performance.

Lastly, the present study made an important revelation that is not presently available in previous study. It was revealed that team self evaluation (TSE) has a significant and positive relationship with Technical Skills (TS). This shows that team leaders/members that constantly evaluates themselves will see the need to improve on the technical skill sets. This self evaluation can then invariably spur improvement in technical skill. Therefore, it is important to understand the importance of the skills areas, skills and competencies that could assist both team leaders and members to improve the performance of their team.

\section{Conclusion and Recommendation}

In conclusion, this study has been able to reveal the important factors (skills) that influence the performance of research team and clusters in UTP. Using the leadership skills and competency developed by (Moore and Rudd, 2004) and Stubb (2005). The structural equation revealed that Human Skill and Team Self evaluation are the two 
critical leadership skills that have a positive and significant effect on performance. The study also revealed that the factors in the model predicts performance with a variance $\left(\mathrm{R}^{2}\right)$ of $0.701(70 \%)$, this implies that there are other factors that are not included in the model that could predict performance.

It could be recommended that focused leadership competency development workshop should be arranged for research team leaders. It is a known bitter truth that human behaviour can not be easily known neither is it easy to manage many people of different background, ideas and philosophy. Such competency and leadership training program will allows team leaders to improve their leadership qualities.

To improve the technical skill set of team members and team leaders, it is recommended that team leaders (leader/deputy leader) should have ambience of industry experience (practically or consulting wise). This will assist in relation with the industry. Thus, the academia and industry gap in Malaysia will be bridged. Also, adjunct faculty staffs should also strengthen the research team. These staffs could be from PETRONAS and its partners. Future direction of this study could include use of qualitative paradigm in the research. The effect of moderators such as age, gender, research experience, industry experience etc could also be investigated.

\section{References}

Appelbaum, S. H., Abdallah, C., \& Shapiro, B. T. (1999). The self-directed team, A Conflict Resolution Analysis. Team Performance Management, 5, 60-77. http://dx.doi.org/10.1108/13527599910268940

Cohen, S. G., \& Bailey, D. W. (1997). What makes teams work: Group effectiveness research from the shop floor to the executive suite. Journal of Management, 23(3), 239-290. http://dx.doi.org/10.1177/014920639702300303

Cronbach, L. J. (1951).Coefficient Alpha and the Internal Structure of Tests. Psychometrika, 16(3), 297-334. http://dx.doi.org/10.1007/BF02310555

Dickson, M. W., Smith, D. B., Grojean, M. W., \& Ehrhart, M. (2001). An organizational climate regarding ethics: the outcome of leader values and the practices that reflect them. The Leadership Quarterly, 12, 197-217. http://dx.doi.org/10.1016/S1048-9843(01)00069-8

Druskat, V. U. (1996). Team-level competencies in superior self-managing manufacturing teams. Paper presented at the Annual Meeting of the Academy of Management, Cincinnati.

Druskat, V. U., \& Wheeler, J. V. (2001). Managing from the boundary: the effective leadership of self-managing work teams. Paper presented at the Annual Academy of Management Meeting, Washington DC.

Druskat, V. U., Wolff, S. B., Koman, E. C. S., \& Messer, T. E. (2003). Emotionally competent group norms and group effectiveness. Paper presented at the Annual Academy of Management Conference, Seattle, Wa.

Dulewicz, V., \& Higgs, M. (2002). Emotional Intelligence: Can it be measured reliably and validly using competency data? In M. Higgs, \& V. Dulewicz (Eds.), Making sense of emotional intelligence. London: ASE

Edmondson, A. (1999). A Safe Harbor: Social Psychological conditions enabling boundary spanning in work teams. In R. Wageman (Ed.), Research on Managing Groups and Teams: Groups in context (pp. 179-199). JAI Press.

Fisher, S. G., Hunter, T. A., \& Macosson, W. D. K. (1997) Team or Group: Managers' Perceptions of the $\begin{array}{lllll}\text { differences. } \quad \text { Journal } & \text { 232-242. }\end{array}$ http://dx.doi.org/10.1108/02683949710174838

Goleman, D. (1998). Working with Emotional Intelligence. New York: Bantam Books.

Goleman, D. (2001). An EI-Based Theory of Performance. In C. Cherniss, \& D. Goleman (Eds.), The Emotionally Intelligent Workplace. San Francisco: Jossey-Bass.

Goleman, D., Boyatzis, R. E., \& McKee, A. (2002). The new leaders: Transforming the art of leadership into the science of results. London: Little, Brown.

Hair, J. F., Anderson, R. E., Tatham, R. L., \& Black, W. C. (2006). Multivariate Analysis (6th ed.). New Jersey: Prentice Hall International.

Hamme, C. (2003). Group Emotional Intelligence, The Research and Development of an Assessment Instrument. Unpublished dissertation, Rutgers State University of New Jersey.

Hirokawa, R. Y., DeGooyer, D., \& Valde, K. (2000). Using Narratives to Study Task Group Effectiveness. Small Group Research, 31, 573-591. http://dx.doi.org/10.1177/104649640003100504 
Hu, L. T., \& Bentler, P. M. (1999). Cutoff Criteria for Fit Indexes in Covariance Structure Analysis: Conventional Criteria Versus New Alternatives. Structural Equation Modeling, 6(1), 1-55. http://dx.doi.org/10.1080/10705519909540118

Katz, R. L. (1955). Skills of an effective administrator. Harvard Business Review, 33(1), 33-42.

Kline, R. B. (2005), Principles and Practice of Structural Equation Modeling (2nd ed.). New York: The Guilford Press.

Koman, E. S., \& Wolff, S. B. (2008). Emotional intelligence competencies in the team and team leader: A multi-level examination of the impact of emotional intelligence on team performance. Journal of Management Development, 27(1), 55-75. http://dx.doi.org/10.1108/02621710810840767

Moore, L. L., \& Rudd, R. D. (2004). Leadership Skills And Competencies For Extension Directors And Administrators. Journal of Agricultural Education, 45(3), 22-33. http://dx.doi.org/10.5032/jae.2004.03022

Moore, L. L., \& Rudd, R. D. (2005). Extension leaders' self-evaluation of leadership skill areas. Journal of Agricultural Education, 46(1), 68-78. http://dx.doi.org/10.5032/jae.2005.01068

Morgan, B. B., Glickman, A. S., Woodard, E. A., Blaiwes, A., \& Salas, E. (1986). Measurement of team behaviors in a Navy Environment. Orlando, FL: Naval Training Systems Center.

Pagon, M., Banutai, E., \& Bizjak, U. (2008). Leadership Competencies For Successful Change Management. A Preliminary Study Report. University of Maribor, Slovenia. Retrieved January 22, 2013, from http://www.dgaep.gov.pt/upload/RI_estudos\%20Presidências/studyseslovenis_LEADERSHIP_COMPETE NCIES.pdf

Patterson, T. F. (1987). Refining performance appraisal. Journal of Extension, 25(4), Retrieved March 22, 2011, from http://www.joe.org/joe/1987winter/a5.html

Schein, E. (1992). Organizational Culture and Leadership (2nd ed.). Jossey-Bass, San Francisco, CA.

Sekaran, U. (2003). Research methods for business (4th ed.). Hoboken, NJ: John Wiley \& Sons.

Shahmandi, E., Silong, A. D., Ismail, I. A., Abu-Samah, A. B., \& Othman, J. (2011). Competencies, Roles and Effective Academic Leadership in World Class University. International Journal of Business Administration, 2(1), 44-53.

Sivasubramaniam, N., Murry, W. D., Avolio, B. J., \& Jung, D. I. (2002). A longitudinal model of the effects of team leadership and group potency on group performance. Group and Organizational Management, 27(1), 66-96. http://dx.doi.org/10.1177/1059601102027001005

Stubbs, E. C. (2005). Emotional Intelligence Competencies in the Team and Team Leader: a Multi-level Examination of the Impact of Emotional Intelligence on Group Performance. PhD Thesis submitted to the Case Western Reserve University.

Stubbs, E. C., \& Messer, T. E. (2002). Team Effectiveness: Assessing the Impact of Group Emotional Competency Norms and the Moderating Role of Task Interdependence, Unpublished Manuscript, Case Western Reserve University.

Winston, M. D., \& Dunkley, L. (2002). Leadership Competencies for Academic Librarians: The importance of Development and Fund-raising. Journal of College \& Research Libraries, 171-182.

\section{Appendix}

\begin{tabular}{ll}
\hline HS & HUMAN SKILL \\
\hline 1 & In our research cluster, we demonstrate respect for others. \\
2 & In our team, our leader is approachable and open to new ideas. \\
3 & I am an effective team member \\
4 & We evaluate the impact of team members \\
5 & We have an effective team leader \\
6 & In our team, we enjoy an environment that values the diversity of others. \\
7 & Personal strengths is identified and appreciated in our team. \\
8 & We have people of complementary strengths \\
9 & Our team demonstrate support for organizational leadership development programs
\end{tabular}




\section{CS CONCEPTUAL SKILL}

In our research cluster:

1 Our leader communicates the research cluster's vision with team members.

2 We exhibit attitude that supports and welcomes organizational change.

3 We help others support organizational change

$4 \quad$ We set goals and achieve set goals.

$5 \quad$ We are critical but creative thinkers.

$6 \quad$ We think strategically by utilizing sequential planning techniques.

TS TECHNICAL SKILL

In our research cluster, our leader:

1 Adjust and Implements departmental budgets to accomplish programs

2 Raise funds from external sources.

3 Work with foundations (Private Sectors \& NGOs)

$4 \quad$ Effectively use computer software for databases

5 Effectively integrate computer program applications (i.e. merge files)

6 Effectively use and search the internet

7 Possess depth of knowledge in the research area

TSE TEAM SELF EVALUATION

In our research cluster:

1 We often discuss what is helping or hurting our performance

2 We try to be aware of our team's mood and how it affects our work

3 We do not evaluate our team and its performance. (R).

$4 \quad$ We often compare ourselves with other teams to see how we are performing

5 We don't spend time evaluating the work done by our team (R)

$6 \quad$ Our team often ask others if they are satisfied with our performance

7 We regularly seek information that will help us evaluate the way we operate

EP EFFECTIVE PERFORMANCE

Our research cluster:

1 Is efficient in getting things done.

2 Produces quality products (Graduates, papers, patents and copyrights)

3 Have the ability to be self directed.

$4 \quad$ Have better performance against all other teams in the faculty and UTP.

5 Team members have the ability to continue working together effectively in the future.

\section{Copyrights}

Copyright for this article is retained by the author(s), with first publication rights granted to the journal.

This is an open-access article distributed under the terms and conditions of the Creative Commons Attribution license (http://creativecommons.org/licenses/by/3.0/). 